\title{
Predictors of maternal mortality among critically ill obstetric patients
}

\section{A S Adeniran'1, B O Bolaji², A A Fawole', O O Oyedepo ${ }^{2}$}

1. Department of Obstetrics and Gynaecology, University of Ilorin / University of Ilorin Teaching Hospital, Ilorin, Nigeria.

2. Department of Anaesthesia, University of Ilorin / University of Ilorin Teaching Hospital, Ilorin, Nigeria.

Correspondance: A S Adeniranu, Email-acrowncord@hotmail.com

\section{Abstract}

\section{Aim}

Evaluation of the predictors of maternal mortality among critically ill obstetric patients managed at the intensive care unit (ICU).

\section{Methods}

A case control study to evaluate the predictors of maternal mortality among critically ill obstetric patients managed at the intensive care unit (ICU) of the University of Ilorin Teaching Hospital, Ilorin, Nigeria from 1st January 2010 to 30th June 2013. Participants were critically ill obstetric patients who were admitted and managed at the ICU during the study period. Subjects were those who died while controls were age and parity matched survivors. Statistical analysis was with SPSS-20 to determine ch square, Cox-regression and odds ratio; $\mathrm{p}$ value $<0.05$ was significant.

\section{Results}

The mean age of subjects and controls were $28.92 \pm 5.09$ versus 29.44 $\pm 5.74(\mathrm{p}=0.736)$, the level of education was higher among controls ( $p$ $=0.048)$ while more subjects were of low social class $(\mathrm{p}=0.321)$, did not have antenatal care $(p=0.131)$ and had partners with lower level of education $(p=0.156)$ compared to controls. The two leading indications for admission among subjects and controls were massive postpartum haemorrhage and severe preeclampsia or eclampsia. The mean duration of admission was higher among controls $(3.32 \pm 2.46$ versus $3.00 \pm 2.58$; $\mathrm{p}=0.656$ ) while the mean cost of ICU care was higher among the subjects $(p=0.472)$. The statistical significant predictors of maternal deaths were the patient's level of education, Glasgow Coma Scale (GCS) score, oxygen saturation, multiple organ failure at ICU admission and the need for mechanical ventilation or inotrophic drugs after admission.

\section{Conclusion}

The clinical state at ICU admission of the critically ill obstetric patients is the major outcome determinant. Therefore, early recognition of the need for ICU care, adequate pre-ICU admission supportive care and prompt transfer will improve the outcome.

\section{Introduction}

Despite efforts towards attainment of the Millennium Development Goals (MDG), maternal mortality remains high in developing countries. As part of efforts at improving maternal health (MDG-5), the management of critically ill obstetric patients stands as an important component. The profile of admission of critically ill obstetric patients has been shown to be similar worldwide ${ }^{1}$; however, there is a clear divide in the mortality with rates of $0 \%$ to $9.4 \% 0^{2-}$ ${ }^{4}$ from developed compared to $33 \%$ to $52 \%$ in developing countries $^{5-8}$. This wide gap is due to a combination of clinical and economic factors with illiteracy, poverty, lack of awareness about health complications, social and behavioural factors, and paucity of research in obstetric critical care playing major roles ${ }^{9}$. In addition, quality obstetric care, well equipped labour wards, evidence-based practice and financial adequacy have reduced the number of obstetric patients requiring critical care and improved the outcome of care in developed countries $^{10}$. Available data from Nigeria and Kenya reported high mortality with obstetric haemorrhage, complications of severe preeclampsia and eclampsia, multiple organ failure, late presentation and lack of antenatal care as major determinants of mortality among critically ill women ${ }^{5-8}$. It has therefore become necessary to gather data on the outcome of the critical care in developing countries to more clearly define the predictors of maternal mortality as well as identify necessary areas for improvement in developing countries. This study aims to evaluate the predictors of maternal mortality among critically ill obstetric patients by comparing survivors and those that died following ICU care in a tertiary center in Ilorin, North central Nigeria.

\section{Materials and Methods}

The study was a retrospective case control study of critically ill obstetric patients who were admitted and managed at the intensive care unit (ICU) of the University of Ilorin Teaching Hospital (UITH), Ilorin, Nigeria from 1st January 2010 to 30th June 2013. The subjects were critically ill obstetric patients who died while controls were the survivors after ICU care. The ICU is a multidisciplinary four bedded unit with facilities for multimodal parameter monitoring and functioning mechanical ventilators. It receives patients from all medical and surgical units in the hospital as well as referrals from other centers. The study was designed as a total population study of all critically ill obstetric patients who died at the ICU matched with equal number of those who survived after ICU care during the study period. The ICU admission register was screened and a list of patients who died during the study period matched with the closest age and parity controls among survivors was compiled; the case files were then retrieved from the medical records department of the hospital for analysis. The matching was to highlight the values of the parameters evaluated among the two groups and provide possible explanations for the maternal deaths. Maternal age and parity were used for matching because these are known independent factors that influence pregnancy outcome and may serve as confounders if not controlled for. The inclusion criteria were admission into the ICU during pregnancy or within 42 days of its termination and the complete management data must be available for review. Exclusion criteria were non-obstetric patients, women admitted after 42 days from the termination of last pregnancy and obstetric patients whose complete management data were not available for review. The main outcome measures were maternal death or survival at the end of the ICU admission.The data obtained included socio-demographic and obstetric parameters, indication and clinical state at ICU admission, care, complications, duration and final outcome of ICU admission. Data analysis was by using the SPSS version-20, chi-square, Cox- regression and odds ratio with 95\% confidence interval were calculated; $p$ value $<0.05$ was termed significant. The data for the study was part of the result of an audit of ICU care in the hospital during the study period; institutional ethical approval was obtained before commencement of the study, sponsorship was by the researchers and there was no conflict of interest in the conduct of the study.

\section{Results}

A total of 90 critically ill obstetric patients received ICU http://dx.doi.org/10.4314/mmj.v27i1.5 
care during the study period; of these, 49 survived while 41 died. However, complete management data was available for only 25 of the women that died (51\% retrieval rate); these 25 represented the subjects while an equal number (25) of age and parity matched women who survived after ICU care during the same period represented the controls and were included in the study. From Table 1, the mean ages (28.92 \pm 5.09 versus $29.44 \pm 5.74 ; \mathrm{p}=0.736)$ and mean parities $(1.80$ \pm 1.53 versus $2.08 \pm 1.55 ; \mathrm{p}=0.523)$ of the controls and subjects were similar. Educational attainment was higher and statistically significant among the controls $(p=0.048$; OR 0.316 , CI $0.1-1.004)$; more subjects were of low social class $(\mathrm{p}=0.321 ;$ OR 2.471 , CI 0.634-9.625), unbooked prenatally $(\mathrm{p}=0.131 ;$ OR 0.390 , CI 0.196-1.891) and had partners with lower level of education ( $p=0.156$; OR 0.442, CI 0.1421.376) compared to controls. In Table 2 , the indications for ICU admission were similar among subjects and controls; the two commonest were massive postpartum haemorrhage (12 versus $7, p=0.2513)$ and severe preeclampsia or eclampsia $(6$ versus $7 ; \mathrm{p}=0.7815)$. The mortality rates were $100 \%$ among those admitted for amniotic fluid embolism, complications of unsafe abortion and peripartum cardiomyopathy. Table 3 shows that the mean duration of admission was higher among controls $(3.32 \pm 2.46$ versus $3.00 \pm 2.58 ; \mathrm{p}=0.656)$ while the mean cost of ICU admission was higher among subjects although not statistically significant $(\mathrm{p}=0.472)$. There was higher occurrence with statistical significance of multiple organ dysfunction $(\mathrm{p}=0.0274$; OR 4.43 , CI 0.96-22.04) and development of further complications after ICU admission ( $\mathrm{p}<0.001$; OR 0.26, CI 0.15-0.46) among subjects compared to controls. In Table 4, the commonest drugs administered were antibiotics $(100 \%)$ in both subjects and controls but there was statistical significance in the use of mechanical ventilators $(\mathrm{p}=0.028)$, oxygen administration via nasal catheter $(p=0.045)$ and use of inotrophic drugs $(p<0.001)$. From Table 5, Cox-regression showed that the major predictors of maternal mortality were the woman's age (regression coefficient -0.004, hazard ratio 0.996), educational status of the woman (regression coefficient -0.335 , hazard ratio 0.715), the Glasgow Coma Scale score at ICU admission (regression coefficient -0.143 , hazard ratio 0.867 ), systolic blood pressure at admission (regression coefficient -0.030 , hazard ratio 0.970) and the SpO2 (regression coefficient -0.011 , hazard ratio 0.989).

Table 1: Socio-demographic characteristics of ICU survivors and those that died

\begin{tabular}{|c|c|c|c|c|c|c|}
\hline \multirow[t]{2}{*}{ Parameter } & \multirow{2}{*}{$\begin{array}{l}\text { Survivers } \\
n=25(\%)\end{array}$} & \multirow{2}{*}{$\begin{array}{l}\text { Dead } \\
n=25(\%)\end{array}$} & \multirow[t]{2}{*}{$\mathrm{x}^{2}$} & \multirow[t]{2}{*}{ p-value } & \multirow[t]{2}{*}{ OR } & \multirow[t]{2}{*}{$95 \% \mathrm{Cl}$} \\
\hline & & & & & & \\
\hline Mean age & $28.92+5.119$ & $29.44 \pm 5.74$ & -0.339 & 0.736 & & \\
\hline Mean parity & $1.80+1.53$ & $2.08+1.55$ & -0.643 & 0.523 & & \\
\hline \multicolumn{7}{|l|}{ Social class } \\
\hline High & $8(32.0)$ & $4(16.0)$ & & & & \\
\hline Low & $17(68.0)$ & $21(84.0)$ & 1.754 & 0.321 & 2.471 & $0.634-9.625$ \\
\hline \multicolumn{7}{|l|}{ Booking status } \\
\hline Booked & $16(64.0)$ & $13(52.0)$ & & & & \\
\hline Unbooked & $9(36.0)$ & $12(48.0)$ & 0.739 & 0.131 & 0.390 & $0.196-1.891$ \\
\hline \multicolumn{7}{|c|}{ Patient's level of education } \\
\hline At most primary & $9(36.0)$ & $16(64.0)$ & & & & \\
\hline Post primary & $16(64.0)$ & $9(36.0)$ & 3.920 & 0.048 & 0.316 & $0.100-1.004$ \\
\hline \multicolumn{7}{|c|}{ Partner's level of education } \\
\hline At most primary & $9(36.0)$ & $14(56.0)$ & & & & \\
\hline Post primary & $16\{64.0\}$ & $11(44.0)$ & 2.013 & 0.156 & 0.442 & $0.142-1.376$ \\
\hline
\end{tabular}

Table 2: Indications for admission into the intensive care unit among survivors and those that died

\begin{tabular}{|c|c|c|c|c|c|}
\hline \multirow[b]{2}{*}{ Indication } & \multicolumn{2}{|c|}{ Final Outcome } & \multirow[b]{2}{*}{$\begin{array}{l}\text { Mortality } \\
\text { index } \\
\mathrm{n}_{2} \mathrm{~N} \times 100\end{array}$} & \multirow[b]{2}{*}{$x^{2}$} & \multirow[b]{2}{*}{ P value } \\
\hline & $\begin{array}{l}\text { Survivors } \\
\mathrm{n}_{1}=25 \\
(\%)\end{array}$ & $\begin{array}{l}\text { Dend } \\
\begin{array}{c}\mathrm{n}_{2}=25 \\
(\%)\end{array}\end{array}$ & & & \\
\hline Massive postpartum hacmorthage & $12(48.0)$ & $7(28.0)$ & 36.8 & & \\
\hline$(\mathrm{N}=19)$ & & & & 1.316 & 0.2513 \\
\hline Severe preeclumpsia/ Felampsia (N-13) & $6(24,0)$ & $7(28.0)$ & 53.9 & 0.077 & 0.7815 \\
\hline HELLP syndrome $(\mathrm{N}=3)$ & $1(4.0)$ & $2(8.0)$ & 66.7 & 0.333 & 0.5637 \\
\hline Amniotic fluid embolism (N=2) & $0(0.0)$ & $2(8.0)$ & 100.0 & - & - \\
\hline Puerperal sepsis (N-3) & $2(8.0)$ & $1(4.0)$ & 33.3 & 0.333 & 0.5637 \\
\hline Uterine rupture $(\mathrm{N}=6$ ) & $4(16.0)$ & $2(8.0)$ & 33.3 & 0.667 & 0.4142 \\
\hline Complication of unsafe abortion ( $\mathrm{N}=2$ ) & $0(0.0)$ & $2(8.0)$ & 100.0 & - & $\cdot$ \\
\hline Peripurium Cardiomyopathy (N-2) & $0(0.0)$ & $2(8.0)$ & 100.0 & . & . \\
\hline
\end{tabular}

Table 3: Intensive care admission parameters, cost and duration among survivors and those that died.

\begin{tabular}{|c|c|c|c|c|c|c|}
\hline Variable & $\begin{array}{l}\text { Survivors } \\
\mathrm{n}=25(\%)\end{array}$ & $\begin{array}{l}\text { Dead } \\
n=25(\%)\end{array}$ & $\mathrm{X}^{2}$ & Pvalue & OR & $95 \% \mathrm{CI}$ \\
\hline \multicolumn{7}{|l|}{ Condition at admission } \\
\hline Pregnant & 0 & $5(20.0)$ & & & & \\
\hline Postpartum & $25(100.0)$ & $17(68.0)$ & 4.19 & 0.0171 & 0.00 & $0.00-0.92$ \\
\hline Post aburtion & 0 & $3(12.0)$ & 1.97 & 0.0803 & 0.00 & $0.00-0.41$ \\
\hline \multicolumn{7}{|l|}{$\mathrm{GCS}$} \\
\hline Mild & $10(40.0)$ & $1(4.0)$ & & & & \\
\hline Moderate & $8(32.0)$ & $7(28.0)$ & 2.63 & 0.0847 & 8.75 & $0.74-23.64$ \\
\hline Severe & $3(28.0)$ & $17(68.0)$ & 1.37 & 0.2410 & 2.78 & $0.60-13.38$ \\
\hline \multicolumn{7}{|l|}{$\mathrm{SPO}_{2}$} \\
\hline Нурохіа & $22(88.0)$ & $20(80.0)$ & & & & \\
\hline Normal & $3(12.0)$ & $5(20.0)$ & 0.595 & 0.702 & 1.83 & $0.32-11.36$ \\
\hline \multicolumn{7}{|l|}{ Respiratory rate } \\
\hline Tachvhpnoca & $23(92.0)$ & 2496.0) & & & & \\
\hline Normal & $2(8.0)$ & $1(4.0)$ & 0.355 & 0.999 & 2.09 & $0.13-62.70$ \\
\hline \multicolumn{7}{|l|}{ Pulse rate } \\
\hline Normal & $9(36.0)$ & $4(16.0)$ & & & & \\
\hline Tachycardia & $16\{64.0\}$ & $21(84.0)$ & 2.599 & 0.196 & 2.95 & $0.66-14.14$ \\
\hline \multicolumn{7}{|l|}{ Systolic BP } \\
\hline$<0$ & 0 & $5(20.0)$ & & & & \\
\hline $90-139$ & $15(60.0)$ & $10(40.0)$ & 3.84 & 0.0421 & 0.00 & $0.00-1.00$ \\
\hline$\geq 140$ & $10(40.0)$ & $10(40.0)$ & 0.14 & 0.7121 & 1.50 & $0.39-5.84$ \\
\hline \multicolumn{7}{|l|}{ Organ dysfunction } \\
\hline None & $6(24.0)$ & $1(4,0)$ & & & & \\
\hline 1 & $15(60.0)$ & $11(44.0)$ & 1.87 & 0.2233 & 4.40 & $0.40-11.68$ \\
\hline$\geq 2$ & $4(16.0)$ & $13(52.0)$ & 4.86 & 0.0274 & 4.43 & $0.96-22.04$ \\
\hline \multicolumn{7}{|l|}{ Complication at ICU } \\
\hline Yes & $9(36.0)$ & $25(100.0)$ & & & & \\
\hline No & $16\{64.0\}$ & 0 & 23.53 & $<0.001$ & 0.26 & $0.15-0.46$ \\
\hline Mean duration of admission & $3.32 \pm 2.46$ & $3.00 \pm 2.58$ & 0.499 & 0.656 & & \\
\hline Mean total cost (naira) & $39020+22895$ & $45600+39162$ & -0.325 & 0.472 & & \\
\hline
\end{tabular}

Table 4: Treatments administered to the survivors and those who died

\begin{tabular}{|c|c|c|c|c|}
\hline \multirow[t]{3}{*}{ Intervention in ICU } & \multicolumn{2}{|c|}{ Final Outeome } & \multirow[t]{3}{*}{$x^{2}$} & \multirow[t]{3}{*}{ Pvalue } \\
\hline & Survivers & Alive & & \\
\hline & $\mathrm{n}=25(\%)$ & $\mathrm{n}=25(\%)$ & & \\
\hline Oxygen administration via nasal catheter & $24(96.0)$ & $12(48.0)$ & 4.19010 & $0.045^{*}$ \\
\hline Mechanical ventilation & $11(44.0)$ & $24(96.0)$ & 4.829 & $0.028 *$ \\
\hline Radiological imaging & $2(8.0)$ & $3(12.0)$ & 0.2110 & 0.654 \\
\hline Renal dialysis & 0 & $4(16.0)$ & $\mathrm{NA}$ & $\mathrm{NA}$ \\
\hline Defribillation & 0 & $4(16.0)$ & $\mathrm{NA}$ & $\mathrm{NA}$ \\
\hline \multicolumn{5}{|l|}{ Drug used } \\
\hline Antibiotics & $25(100.0)$ & $25(100.0)$ & $\mathrm{N} \Lambda$ & NA \\
\hline Antihypertensives & $10(40.0)$ & $6(24.0)$ & 1.00 & 0.317 \\
\hline Magnessium sulphate & $9(36.0)$ & $5(20.0)$ & 1.143 & 0.285 \\
\hline Inotrophic drugs & $4(16.0)$ & $22(88.0)$ & 12.462 & $<0.001$ \\
\hline Anticongulant & $1(4.0)$ & $3(12.0)$ & 1.000 & 0.317 \\
\hline Mannitol & $1(4.0)$ & $3(12.0)$ & 1.090 & 0.317 \\
\hline Antiplatelets & $3(12.0)$ & $6(24.0)$ & 1.000 & 0.317 \\
\hline Diuretic & $1(4.1)$ & $3(12.0)$ & 1.000 & 0.317 \\
\hline
\end{tabular}


Table 5: Predictors of Mortality using the Cox - regression analysis

\begin{tabular}{|c|c|c|c|c|c|}
\hline \multirow[t]{2}{*}{ Variahle } & \multirow[t]{2}{*}{$\begin{array}{l}\text { Regression } \\
\text { coefficient }\end{array}$} & \multirow[t]{2}{*}{ P value } & \multirow[t]{2}{*}{$\begin{array}{c}\text { Hazard } \\
\text { ratio }\end{array}$} & \multicolumn{2}{|c|}{$\begin{array}{l}95 \% \text { Cl for hazard } \\
\text { ratio }\end{array}$} \\
\hline & & & & Lower & Upper \\
\hline $\mathrm{Age}$ & -0.004 & 0.948 & 0.996 & 0.895 & 1.110 \\
\hline Parity & 0.014 & 0.946 & 1.014 & 0.680 & 1.512 \\
\hline Social class & 0.277 & 0.661 & 1.319 & 0.383 & 4.545 \\
\hline Fducational status & -0.335 & 0.628 & 0.715 & 0.185 & 2.773 \\
\hline Marital status & 0.950 & 0.296 & 2.586 & 0.435 & 15.363 \\
\hline Booking status & 0.247 & 0.651 & 1.280 & 0.439 & 3.733 \\
\hline GCS & -0.143 & 0.035 & 0.867 & 0.759 & 0.990 \\
\hline SBP & -0.030 & 0.036 & 0.970 & 0.943 & 0.998 \\
\hline DBP & 0.046 & 0.031 & 1.047 & 1.004 & 1.092 \\
\hline $\mathrm{SPO}_{2}$ & -0.011 & 0.557 & 0.989 & 0.953 & 1.026 \\
\hline Pulse rate & 0.004 & 0.800 & 1.004 & 0.972 & 1.038 \\
\hline Respiratory rate & 0.037 & 0.130 & 1.038 & 0.989 & 1.090 \\
\hline Organ dysfunction at admission & 0.585 & 0.612 & 0.557 & 0.058 & 5.347 \\
\hline
\end{tabular}

\section{Discussion}

In this study, the predictors of maternal mortality among critically ill obstetric patients managed at the ICU were the level of education of the woman, the clinical state on admission at the ICU in terms of the Glasgow Coma Scale score, oxygen saturation, respiratory rate and presence of multiple organ failures. Others were the need for use of inotrophic drugs, mechanical ventilator and occurrence of further complications during ICU admission. Also, the hazard risk of dying on Cox-regression analysis was higher with respect to the age and educational status of the woman, the GCS, systolic blood pressure and oxygen saturation at ICU admission. However, the parity, booking status, diagnosis at ICU admission, mean duration of ICU admission and mean cost of care were not significant in predicting mortality. The woman's educational level stood out as a major predictor of outcome of care in critically ill obstetric patients in this study. This corroborates previous studies that female education improves the health seeking behaviour of a woman as well as her general attitude to health matters ${ }^{1}$. This further emphasizes the role of universal basic education especially for the girl child in the achievement of the Millennium Development Goals (especially MDGs 4 and 5). Although many researchers have not linked age with mortality in critically ill obstetric patients, Waterhouse et al., reported that mortality is worse in women $>34$ years of age ${ }^{11}$; this study also showed a higher hazard risk of dying with age in critically ill obstetric patients. This means that the older the woman, the higher her risk of dying when critically ill. Multiple organ failure has been reported to be a major predictor of mortality in critically ill obstetric patients by previous researchers, ${ }^{5,6,12,13}$ which was further validated in this study. This may be because it is a reflection of the severity of the illness and expectedly the outcome. It may also show the effect of poor recognition of complications and late presentation for care ${ }^{6}$ until when irreversible cellular damage would have occurred. This further predisposes to the need for inotrophic drugs and mechanical ventilation to support these failed organs with a risk of developing further complications in the ICU as reported in this study thereby reducing the chance of survival. Osinaike et al., in Ibadan,
Nigeria reported that the need to use inotrophic drugs and mechanical ventilation were predictors of maternal mortality ${ }^{14}$. Unlike the reports of Okafor et al., ${ }^{6}$ and Karnad et al., ${ }^{15}$ that absence of prenatal care was a predictor of maternal mortality in critically ill obstetric patients, the booking status in this study was not a predictor of mortality. This could be because the delay in recognition of the need for ICU care and delays in presentation could have removed the otherwise expected beneficial effect of prenatal care. Although the pattern of diagnosis on admission was similar between the subjects and controls, the mortality indices were highest in those with complications of unsafe abortion, peripartum cardiomyopathy and amniotic fluid embolism (AFE; both cases were presumptive diagnoses). AFE and peripartum cardiomyopathy were associated with high mortalities while unsafe abortion and its complications remain a major problem in countries with restrictive or prohibitive abortion laws like Nigeria. In such places unsafe abortions are common and only women with significant morbidity present at the hospital for treatment ${ }^{16}$ with the resultant higher risk of maternal mortality.

Although not statistically significant, complications of preeclampsia and eclampsia and massive postpartum haemorrhage remain important causes of death in the study. This was similar to the reports of Okafor et al., ${ }^{6}$ where these diagnoses featured prominently among the causes of death among critically ill obstetric patients. However, the lower mortality index following massive PPH in this study could be partly due to easier availability of blood and blood products in this center contrary to the report of Okafor et al., ${ }^{6}$ with significant limitations in obtaining them. This is because of our institutional policy of compulsory antenatal blood donation of one unit of blood on behalf of each antenatal care attendee which enabled the center to cater for the blood need of both booked and unbooked women. In this center, admission deposit is not insisted upon before admission into the ICU; there is also an institutional provision for deferment of payment for all emergencies while all interventions including surgeries are performed. This may explain why the social class was not a predictor of maternal mortality in this study as these institutional policies bridged the gap for the women of low social class.

\section{Conclusion}

The clinical state of the critically ill obstetric patients at admission into the ICU remains the major determinant of the outcome of ICU care; thus, early recognition of the need for ICU care, adequate pre-ICU resuscitation and supportive care and prompt referral will improve the outcome of care. The limitations of the study include the relatively small sample size, which may be a reflection of ICU utilization in this environment and the short study period. The major limitation is the low retrieval rate of complete management data; this remains a major challenge in resource challenged countries like Nigeria where hospital data are largely not fully computerized. We recommend that health facilities especially in resource challenged countries should pursue full computerization of hospital data to avert cases of missing data.

\section{References}

1. Pollock W, Rose L, Dennis C. Pregnant and postpartum admission to intensive care unit: a systematic review. Intensive Care Med. 2010; 36(9): 1465-1474. 
2. Muench MV, Baschat AA, Malinow AM, Mighty HE. Analysis of disease in the obstetric intensive care unit at a University referral center: a 24 month review of prospective data. J Reprod Med. 2008; 53(12):914-920

3. Siriam S, Robertson MS. Critically ill obstetric patients in Australia: a retrospective audit of 8 year experience in a tertiary intensive care unit. Crit Care Resusc. 2008; 10: 120-124.

4. Al- Suleiman SA, Qutub HO, Rahman J, Rahman SM. Obstetric admissions to the intensive care unit: a 12 year review. Arch Gynecol Obstet. 2006; 274: 4-8.

5. Faponle AF, Adenekan OT. Obstetric admissions into the intensive care unit in a sub-urban University Teaching Hospital. NJOG. 2011; 6(2): 33-36.

6. Okafor VU, Efetie ER, Amucheazi A. Risk factors for maternal deaths in unplanned obstetric admissions to the intensive care unit- Lessons for sub-Saharan Africa. Afr J Reprod Health. 2011; 15(4):51-54.

7. Githae F, Mung'ayi V, Stones W. Course and outcome of obstetric patients admitted to a University hospital intensive care unit. East Afr Med J. 2011; 88(10): 356-360

8. Anwari JS, Butt AA, Al-Dar MA. Obstetric admissions to the intensive care unit. Saudi Med J. 2004; 25(10): 1394-1399.

9. Lapinsky SE, Kruczynski K, Seaward GR, Farine D, Grossman RF. Critical care management of the Obstetric patient. Can J Anaes. 1997; 44(3):325-329.
10. Kilpatrick SJ, Matthay MA. Obstetric patients requiring critical care: A five-year review. Chest. 1992; 101(5): 1402-1412.

11. Waterhouse M, Bewley S, Wolfe C. Incidence and predictors of severe obstetric morbidity: case control study. BMJ 2001; 322: 10891094.

12. Department of Health / NHS executive. Guidelines on admission to and discharge from intensive care and high dependency units. London: DOH; 1996.

13. Zeeman GG. Obstetric critical care: a blueprint for improved outcomes. Crit Care Med. 2006; 34(9 supp): S208-214

14. Osinaike B, Amanor-Boadu S, Sanusi A. Obstetric intensive care: A Developing Country Experience. The Internet J Anaes 2005; 10(2).

15. Karnad DR, Lapsia V,Krishnan A, Salvi VS. Prognostic factors in obstetric patients admitted into an Indian intensive care unit. Crit Care Med. 2004; 32(6):1294-1299.

16. Bhat PBR, Navada MH, Rao SV, Nagaratna G. Evaluation of obstetric admissions to intensive care unit of a tertiary referral center in coastal India. J Crit Care Med. 2013; 17(1): 34-37. 